\title{
Generalized Economic Order Quantity Inventory Model using Brownian Motion in Food Production Planning
}

\author{
K. Suganthi, G. Jayalalitha
}

\begin{abstract}
The goal of this paper is to propose a Generalized EOQ inventory model, which combines Inventory replenishment and pricing decisions for perishable product in an Inventory model. The Stochastic Demandrequests for new and old items are derivedvia linear functions of their cost. The proposed solution obtains from the optimum system solution, such as food Procurement price, Shortage cost, Purchasing cost, Operational cost and Total costare reduced. A Mathematical model is introduced along with differential matrix to find optimal solutions for the Inventory method in food production planning. Numerical example and Sensitivity Analysis are explained in the proposed system. Brownian Motion are found from Cycle Length ( $L=1.1$ to 1.5). The Brownian Motionanalyses all the costs and plays a major part to reduce it further.
\end{abstract}

Keywords: Inventory Model, EOQ, Shortage Price, Stochastic Demand, Brownian Motion.

AMS Classifications: 90B05, 90B36, 90B99, 60JXX, $60 \mathrm{~J} 65$.

\section{INTRODUCTION}

Irregular movement of tiny elements suspended in a liquid or a gas, produced by the bombardment of the elements by molecules. Firstnoticed by Robert Brown in 1827[1, 12]. Production planning also make sure that staffing is sufficient, that food is in-house, basic preparation steps are completed, foods are soften correctly, and several other functions are done [11]. Stock affiliation ends up one fundamental thing that should be considered by the affiliation related to the remuneration of the alliance especially with the points of interest contained in the stock [1]. Having a lot of stock has an eventual outcome of the unit of central focuses for various parts in the relationship since by far most by far of the points of interest are set assets into the stock. On the other hand, having less stock in hands will make the probability of the unfilled intrigue, and this will price the reputation of the association later on [2][3].

Hence, we need a reasonable model to find the perfect stock to help connection dealing with this issue. Starting late, predictable bits of knowledge have been used in different areas, everything considered, issues, particularly for controlling stock [4].

Revised Manuscript Received on December 5, 2019.

K. Suganthi, Research Scholar, Department of Mathematics, VELS Institute of Science Technology \& Advanced Studies- Chennai, Tamil Nadu, India. Email: suganthi19122012@gmail.com.

G. Jayalalitha, Professor, Department of Mathematics, VELS Institute of Science Technology \& Advanced Studies- Chennai, Tamil Nadu, India. Email: g.jayalalithamaths.sbs@velsuniv.ac.in
One of the most significant stresses of the affiliation is to pick when and the total to compose or to pass on so the unmitigated price related with the stock structure should be least [5]. This is somewhat reliably essential, when the stock experience decay or disintegrating. Isolating is portrayed as change, hurt, ruin, and crippling outdated quality. [6]. It is unprecedented that particular things, for instance, vegetable, prescription, fuel, blood and radioactive planned substances decay under disintegrating during their normal social affair period. As such, while picking the perfect stock technique of that kind of things, the disaster on account of rot can't be rejected [7]. A stunning referencing procedure for upstream supply sort out, considering negative relationship of retailer forms between periods. This dynamic system may instigate astonishing execution improvements [8].

The perfect purchase and stock recuperation issue of temporary standard plant thing, in which the distributer needs to pick the aggregate to buy in the accumulate season and the entire to recoup from the forcedmoving away in each period to offer to the market [9]. Stock controlling issue (IRP) model [10] grants to separate the upsides of level joint exertion with related to a few chiefaction pointers, i.e., transmissions, dynamic time, full scale price included sorting out, stock and waste price given a scrappy intrigue. A mixed entire number nonlinear programming model [11] is used to restrict the full scale expenses using two counts and Lindo impacts of unequivocal components, for instance, the proportion of workplaces, perfect rates and deals on the unbending prices. A budgetary deals complete stock model [12] with screening price and pointless price at two area coordination plan pondered buyer in non coordination develop and no insufficiencies for coordination plot. In context on the upsetting materials, the sustenance business is looked with tangled stock affiliation issues because of the concise natures. Since green things ruin after some time, it is key for stock heads to use an affiliation procedure to neutralize some portion of the course of action time span [11]. The free show off movement of country and marine things impact in a general sense with climatic blends, conflicting changes and unquestionable social parts. Reclamation decisions for brief things are attempting an outcome of vulnerabilities in customer demand, achieved by bound thing time extent of ease of use and pricemarkdowns [7].

\section{PROBLEM DEFINITION}

The following assumptions and notations are used to develop the model

Notations:

$\mathrm{W}_{2}$ - Buyer setup price

$\mathrm{w}_{1}$ - Buyer holding price

C - Production rate for

manufactures 
$\mathrm{R}$ - Size of the back orders

$\mathrm{V}_{1}$ - Manufacture setup price

$\mathrm{V}_{2}$ - Manufacture holding price

$\mathrm{L}$-Cycle length

$\mathrm{F}_{\mathrm{c}}$ - Food Procurement Price

$\mathrm{S}$ - Operation price per growing period

Q-Storage quaintly

$\mathrm{P}_{\mathrm{c}}$ - Total buyingprice

$\mathrm{T}_{\mathrm{c}}$ - Total price

Aninventory scheme for standard things like books, set sustenance and different things, where the provider gets them and stock them for a level of time, $\mathrm{x} 1$; by at that point, things are traded at a rate, i.e., request rate $\mathrm{d}$, until the stock level gets in contact at zero. At last, during x3, the stock structure faces need until the time that the level of need interfaces at Q.

$$
\begin{gathered}
x_{1}=\frac{W_{1}-W_{0}}{u R}=\frac{v_{1}-v_{0}}{R} \\
x_{2}=\frac{W_{2}}{d}=\frac{u v_{1}-Q}{d} \\
x_{3}=\frac{Q}{d}=\frac{Q}{d}
\end{gathered}
$$

Hence, cycle length is computed as

$$
L=x_{2}+x_{3}=\frac{u v_{1}-Q}{d}+\frac{Q}{d}=\frac{u v_{1}}{d}
$$

Hence $u=\frac{d L}{v_{1}}$

The aim of themethod is to minimizecomplete price per period $\left(\mathrm{T}_{\mathrm{C}}\right)$ comprisingbuyingprice $\left(\mathrm{P}_{\mathrm{C}}\right)$, holding price $\left(\mathrm{H}_{\mathrm{C}}\right)$, operational prices $\left(\mathrm{O}_{\mathrm{C}}\right)$, shortage price $\left(\mathrm{S}_{\mathrm{C}}\right)$ and food acquirement price $\left(\mathrm{F}_{\mathrm{C}}\right)$. This is represented as follows.

$$
T_{C}=P_{C}+H_{C}+O_{C}+S_{C}+F_{C}
$$

The next subdivision explains a complete analysis of computation of earlier discussed prices.

\section{A. Buying Price For Each Time}

The costfor every gramispso the whole buyingpricefor each timeachieved by equation (7)

$$
P_{C}=p u v_{0}
$$

By substituting $\mathrm{u}$ from equation (5), we have

$$
P_{C}=p v_{0}\left(\frac{D T}{v_{1}}\right)
$$

\section{B. Holding Price For Each Time}

Holding pricefor every gram per time period isfadditionally, holding price is computed at the final stage of growing period ( $\mathrm{x} 2)$. Holding price per period is described as

$$
H_{C}=f\left(\frac{x_{2} W_{1}}{2}\right)=f\left(\frac{\left(u v_{1}-Q\right)^{2}}{2 d}\right)
$$

$$
\begin{aligned}
& H_{C}=\frac{f}{2 d}\left[\left(u v_{1}\right)^{2}+(Q)^{2}-2 u v_{1} Q\right] \\
& H_{C}=\frac{f Q^{2}}{2 d}-f T S+\frac{f d L^{2}}{2}
\end{aligned}
$$

\section{Operational Prices Per Time Interval}

Operational price per risingtime interval is $S$, so we have

$$
O_{C}=S L C
$$

\section{Shortage Price}

Shortage pricefor every gram per time intervalis $g$. Total shortage prices can be computed as

$$
S_{C}=g\left(\frac{x_{3} Q}{2}\right)=g\left(\frac{Q^{2}}{2 d}\right) \mathrm{L}
$$

\section{E. Food Procurement Price For Each Time}

Food Procurement price for every gram per time intervalis $c$.Food Procurement prices per period, is calculated as

$F_{C}=c \frac{x_{1}\left(W_{1}-W_{2}\right)}{2}=c\left(\frac{u\left(v_{1}-v_{0}\right)^{2}}{2 R}\right)$

By substituting $\mathrm{u}$ from equation (5), we have

$$
F_{C}=\frac{d c\left(v_{1}-v_{0}\right)^{2} L}{2 R v_{1}}
$$

With respect to equation (8), (10-12) and (14), the inventory whole pricesfor each time unit are formulatedas follows

$$
\begin{gathered}
T_{C}=P_{C}+H_{C}+O_{C}+S_{C}+F_{C} \\
T_{C}=d p v_{0}\left(\frac{D T}{v_{1}}\right)+\frac{f Q^{2}}{2 d}-f T S+\frac{f d L^{2}}{2}+S+g\left(\frac{Q^{2}}{2 d}\right)+ \\
\frac{d c\left(v_{1}-v_{0}\right)^{2} L}{2 R v_{1}}
\end{gathered}
$$

Therefore, total inventory pricefor each unit time is calculated as follows,

$$
\begin{array}{r}
T_{C}=\frac{T C U}{T}=\frac{d p v_{0}}{v_{1}}+\frac{d c\left(v_{1}-v_{0}\right)^{2}}{2 R v_{1}}+S\left(\frac{1}{L}\right)+\left(\frac{f+g}{2 d}\right)\left(\frac{(Q)^{2}}{L}\right)+ \\
\frac{f d}{2}(L)-f(Q)
\end{array}
$$

\section{F. Constraint}

Our inventory system assures that objects are available to utilize on time, the entire setup and development time shouldbe less than or equal to usage and shortage time. Hence, the below mentionedparameter should be fulfilled:

$$
x_{1}+x_{s} \leq L
$$

Substituting, $x_{1}$ from equ 1 , obtains the following constraint: 


$$
\frac{v_{1}-v_{0}}{R}+x_{s} \leq L
$$

By substituting $u$ from equ 5 transforms, thisparameter into the following for production time:

$$
L \geq\left\{\frac{v_{1}-v_{0}}{R}+x_{s}=L_{\text {min }}\right\}
$$

\section{G. Mathematical Expression Of The Eoq Inventory Method With Increasing Materials}

As per the equation 16 and equation 19, the mathematical formation of the EOQ inventory method with developing objectsis mentioned as

$$
\begin{gathered}
\operatorname{Min} T_{C}=\left\{\frac{d p v_{0}}{v_{1}}+\frac{d c\left(v_{1}-v_{0}\right)^{2}}{2 R v_{1}}+S\left(\frac{1}{L}\right)+\left(\frac{f+g}{2 d}\right)\left(\frac{(Q)^{2}}{L}\right)+\right. \\
f d 2 L-f Q
\end{gathered}
$$

Such that, $T \geq T_{\min }$

$$
\begin{aligned}
& S \geq 0 \\
& T>0
\end{aligned}
$$

\section{SOLUTION PROCEDURE}

The objective function of the proposed issue (equation 20) is calculated. Then again, the proposed numerical model has a straight essential, this coherent model is a twisted unsurprising non-direct programming. Bended goods imparts that if a reachable game-plan crushes its surroundings, i.e., close by optima, by then it is by and large optima also. Consequently, the ideal game-plan of the goal work (equation 20) is managed by utilizing fragmentary subordinates. Figuring the inadequate helper of the goal work (equation 20) as for the cycle-length (L) and making it proportionate to zero, the ideal game-plan of $\mathrm{L}$ is as per the going with:

$$
\begin{gathered}
\frac{\partial T_{c}}{\partial L}=\frac{-S-\left(\frac{f+g}{2 d}\right) Q^{2}}{L^{2}}+\frac{f d}{2} \\
=0 \rightarrow L=\sqrt{\frac{2 d S+(f+g) Q^{2}}{f d^{2}}}
\end{gathered}
$$

Additionally, computing the partial derivative of objective function (equation20) with related to the deficiency amount (Q) and converting it nearby zero, the minimal solution of $\mathrm{Q}$ is as follows:

$$
\frac{\partial T_{c}}{\partial Q}=\left(\frac{f+g}{d L}\right) Q-f=0 \rightarrow Q=\frac{f d L c}{f+g}
$$

Substituting Q from equation 22 in equation 21, the optimum cycle length is computed as follows:

$$
L=\sqrt{\frac{2 d S}{f d^{2}\left(1-\frac{f}{f+g}\right)}}
$$

Finally, as per the proposed ideas and formulas, solution stages of the optimization algorithm

For the suggested EOQ inventory system is

Step $1 \quad$ Calculate $L_{\min }$ from equ 19

Step 2 If $L_{\min } \geq 0$ then question is possible and go to Step 3, else it is not possible and stop.

Step 3 If $1-f /(f+g)$ is positive, then problem is infeasible and compute $\mathrm{L}$, else problem is impossible and stop

Step $4 \quad$ Compute $L$ from equ 23.

Step 5 If $L \geq L_{\text {min }}$, then $L^{*}=L$, else $L^{*}=L_{\text {min }}$.

Step $6 \quad$ Calculate $L$ from equ 23.

Step 7 Calculate $T_{c}^{*}$ and $y^{*}$ through objective function of (equ 20) and equ 5, correspondingly, with respect to the achieved $L^{*}$ and $Q^{*}$, and describe the optimal solution.

Step 8 End

\section{NUMERICAL EXAMPLE}

\section{Example:}

Consider a production method with one item and the following values for the input factors. $D=1000, f=0.9, g=0.2$, $R=10, V_{l}=3, V_{0}=0.6, S=11, d=5, p=120$, and the index of the power demand pattern $F_{c}=5.28, Q=45, S_{c}=40.5, O_{c}=121$ and $T_{c}=299.39$

In Table 1, by fixing the replacement rate constraint, if the unit production pricerises then the total profit function and the best lot size and the value of decrease. In this subsection, the effect of factors on choice factors and the target capacity is examined. To do as such, the estimation of every parameter is changed by leaving different factors unaltered.Conversely, the most useful cycle length and the most efficient charge grows in the similar condition. In the equal Table 1, the unit production fee is fixed, the whole earnings function, somewhat, the bestdevelopment time and the economic huge volume reduces as the production rate rises. Conversely, the foremost ratedoes not change in the similar situation. For the Brownian approximation is blocking base-stock and conditional threshold procedures, whereas considering to reactive procedures. It recognise the parametermanagement in which preventive or reactive insurance procedures are most excellent in the Brownian model with respective to the shortfall drifts and minute variance factors. The relative values of maintaining and backorder prices have a consequences on the borderamong the blocking and conditional areas changeability in production and demandperforms no function. This border demonstration might also replicate the significance of managing inventory prices in this regime is obligatory to use the conditional supply to morequantity to make up for the lack of important capacity, and so inventory price is the last price that can be successfully handled. 
When the foremost ability is conditional capability is used often resolve giant inventory shortfalls. shortfall may every so often take excursions to excessive degrees due to variability in demand and manufacturing but, barring for the most serious shortfall spikes, the shortfall improves satisfactorily besides the aid of the conditional supply. The most important capability islarger such that the movement of the shortfall with only fundamental potential is powerful towards the origin, which involves a complete inventory. The Inventory of variability in the demand and the manufacturing tactics in finding out the most fulfilling policy in this system is focussed by means of the reactive vicinity border, which consists of no pricefactors.

The Table 2 values are obtained from Table 1. For the cycle length of L (1.1 to 1.5), the mean of Fc, Sc, Q, Oc and Tc are found and tabulated in table 2.

The Brownianmotion plot of cycle Length( $\mathrm{L}=1.1$ to 1.5$)$, is shown in Figure 1, 2, 3, 4 and 5 respectively.

\section{CONCLUSION}

An EOQ inventory model is proposed, which combines inventory replenishment and valuing choices for item in an inventory system. The stochastic Demand requests for new and old items passed on by means of direct elements of their costs. This model with differential matrix is utilized to get ideal answer for this inventory system. All these factors are analyzed with respective to the food production planning. The demand of a product is described by means of linear functions of their costs. Various cost factors involved to buy a product, maintenance, total and other costs are reduced. The Brownian Motion goes about as a significant job to decrease the cost further.

\section{REFERENCES}

1. Morters P. and Peters Y. Brownian Motion, Cambridge University Press, Cambridge.2010.

2. Duong, L.N., Wood, L.C. and Wang, W.Y., 2015. A multi-criteria inventory management system for perishable \& substitutable products. Procedia Manufacturing, 2, pp.66-76.

3. Wu, T., Shen, H. and Zhu, C., 2015. A multi-period location model with transportation economies-of-scale and perishable inventory. International Journal of Production Economics, 169, pp.343-349.

4. Mirzaei, S. and Seifi, A., 2015. Considering lost sale in inventory routing problems for perishable goods. Computers \& Industrial Engineering, 87, pp. 213-227.

5. Afshar-Nadjafi, B.,2016. The influence of sale announcement on the optimal policy of an inventory system with perishable items. Journal of Retailing and Consumer Services, 31, pp.239-245.

6. Yantong, L.I., Feng, C.H.U., Zhen, Y.A.N.G. and Calvo, R.W., 2016. A production inventory routing planning for perishable food with quality consideration. Ifac-Papersonline, 49(3), pp.407-412.

7. Li, Y., Chu, F. and Chen, K., 2017. Coordinated Production Inventory Routing Planning for Perishable Food. Ifac-Papersonline, 50(1), pp.4246-4251.

8. Minner, S. and Transchel, S., 2017. Order variability in perishable product supply chains. European Journal of Operational Research, 260(1), pp.93-107.

9. Liu, H., Zhang, J., Zhou, C. and Ru, Y., 2018. Optimal purchase and inventory retrieval procedures for perishable seasonal agricultural products. Omega, 79, pp.133-145.

10. Soysal, M., Bloemhof-Ruwaard, J.M., Haijema, R. and van der Vorst, J.G., 2018. Modeling a green inventory routing problem for perishable products with horizontal collaboration. Computers \& Operations Research, 89, pp.168-182.

11. Lawrence Imeokparia, Inventory Management System and Performance of Food and Beverages Companies in Nigeria, IOSR Journal of Mathematics (IOSR-JM) e-ISSN: 2278-5728.Volume 6, Issue 1 PP 24-30(2013).

12. Mandelbrot.B.B., The Fractal Geometry of Nature, Freeman, San Francisco, CA, 1982.

\section{AUTHORS PROFILE}

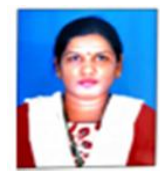

K.Suganthi, Research Scholar,Department of Mathematics, VELS Institute of Science Technology \& Advanced Studies, Chennai, Tamil Nadu, India I have published 3 papers in International Journal and presented 4 papers in International Conference.

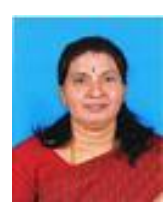

G. JayalalithaM.Sc., M.Phil., Ph.D. Professor, Department of Mathematics, VISTAS, Chennai. She is research Supervisor and She is produced $3 \mathrm{Ph} . \mathrm{D}$. and pursuing 8 scholar under her guidance. She has published more than 40 papers in International Journal and presented various International conference.

Table 1 Optimal procedures for the EOQ system in Food Production planning

\begin{tabular}{|c|c|c|c|c|c|c|}
\hline \multicolumn{2}{|c|}{.$L$} & $F_{c}$ & Sc & $Q$ & $O_{C}$ & $T_{c}$ \\
\hline \multirow[t]{5}{*}{1.1} & $\mathrm{c}=10$ & 5.28 & 40.5 & 45 & 121 & 299.39 \\
\hline & $\mathrm{c}=15$ & 7.92 & 91.13 & 67.5 & 181.5 & 534.55 \\
\hline & $c=20$ & 10.56 & 162 & 90 & 242 & 871.08 \\
\hline & $c=25$ & 13.2 & 253.13 & 112.5 & 302.5 & 1310.88 \\
\hline & $c=30$ & 15.84 & 364.5 & 135 & 363 & 1308.89 \\
\hline \multirow[t]{5}{*}{1.2} & $c=10$ & 5.76 & 48.20 & 49.09 & 132 & 313.11 \\
\hline & $c=15$ & 8.64 & 108.45 & 73.63 & 198 & 569.74 \\
\hline & $c=20$ & 11.52 & 192.79 & 98.18 & 264 & 846.78 \\
\hline & $c=25$ & 14.4 & 301.24 & 122.72 & 330 & 1414.61 \\
\hline & $\mathrm{c}=30$ & 17.28 & 433.79 & 147.27 & 396 & 2001.83 \\
\hline \multirow[t]{4}{*}{1.3} & $\mathrm{c}=10$ & 6.24 & 56.57 & 53.18 & 143 & 328.32 \\
\hline & $c=15$ & 9.36 & 127.27 & 79.77 & 214.5 & 605.93 \\
\hline & $c=20$ & 12.48 & 226.26 & 106.36 & 286 & 1003.17 \\
\hline & $c=25$ & 15.6 & 353.54 & 132.95 & 357.5 & 1520.07 \\
\hline \multicolumn{4}{|c|}{$\begin{array}{l}\text { ieval Number: D10021284S519/2019๑BEIESP } \\
\text { :10.35940/ijrte.D1002.1284S519 }\end{array}$} & $\begin{array}{l}\text { Published } \\
\text { Blue Eyes } \\
\text { \& Sciences }\end{array}$ & ering & \\
\hline
\end{tabular}


International Journal of Recent Technology and Engineering (IJRTE) ISSN: 2277-3878, Volume-8 Issue-4S5, December 2019

\begin{tabular}{|l|c|c|c|c|c|c|}
\hline & $\mathrm{c}=30$ & 18.72 & 509.1 & 159.54 & 429 & 2156.62 \\
\hline 1.4 & $\mathrm{c}=10$ & 6.72 & 65.60 & 57.27 & 154 & 763.67 \\
\hline & $\mathrm{c}=15$ & 10.08 & 147.61 & 85.90 & 231 & 682.18 \\
\hline & $\mathrm{c}=20$ & 13.44 & 262.41 & 114.54 & 308 & 1068.33 \\
\hline & $\mathrm{c}=25$ & 16.8 & 410.02 & 143.18 & 385 & 1624.89 \\
\hline & $\mathrm{c}=30$ & 20.16 & 590.43 & 171.81 & 462 & 2309.58 \\
\hline 1.5 & $\mathrm{c}=10$ & 7.2 & 75.31 & 61.36 & 165 & 353.79 \\
\hline & $\mathrm{c}=15$ & 10.8 & 169.45 & 92.05 & 247.5 & 672.53 \\
\hline & $\mathrm{c}=20$ & 14.4 & 301.24 & 122.72 & 330 & 1134.27 \\
\hline & $\mathrm{c}=25$ & 18 & 470.69 & 153.41 & 412.5 & 1724.02 \\
\hline & $\mathrm{c}=30$ & 21.6 & 677.79 & 184.09 & 495 & 2464.63 \\
\hline
\end{tabular}

Table 2: Procedure of Cycle Length in Brownian Motion

\begin{tabular}{|c|c|c|c|c|c|}
\hline Length Cycle & $F c$ & $S c$ & $Q$ & $O c$ & $T c$ \\
\hline $\mathrm{L}=1.1$ & $\mathrm{M}=10.56$ & $\mathrm{M}=182.25$ & $\mathrm{M}=90$ & $\mathrm{M}=242$ & $\mathrm{M}=864.96$ \\
\hline $\mathrm{L}=1.2$ & $\mathrm{M}=11.52$ & $\mathrm{M}=216.89$ & $\mathrm{M}=98.18$ & $\mathrm{M}=264$ & $\mathrm{M}=1029.05$ \\
\hline $\mathrm{L}=1.3$ & $\mathrm{M}=12.48$ & $\mathrm{M}=254.55$ & $\mathrm{M}=106.36$ & $\mathrm{M}=286$ & $\mathrm{M}=1122.82$ \\
\hline $\mathrm{L}=1.4$ & $\mathrm{M}=13.44$ & $\mathrm{M}=295.21$ & $\mathrm{M}=114.54$ & $\mathrm{M}=308$ & $\mathrm{M}=1289.73$ \\
\hline $\mathrm{L}=1.5$ & $\mathrm{M}=14.4$ & $\mathrm{M}=338.90$ & $\mathrm{M}=122.73$ & $\mathrm{M}=330$ & $\mathrm{M}=1269.85$ \\
\hline
\end{tabular}

$(\mathrm{M}=$ Mean $)$

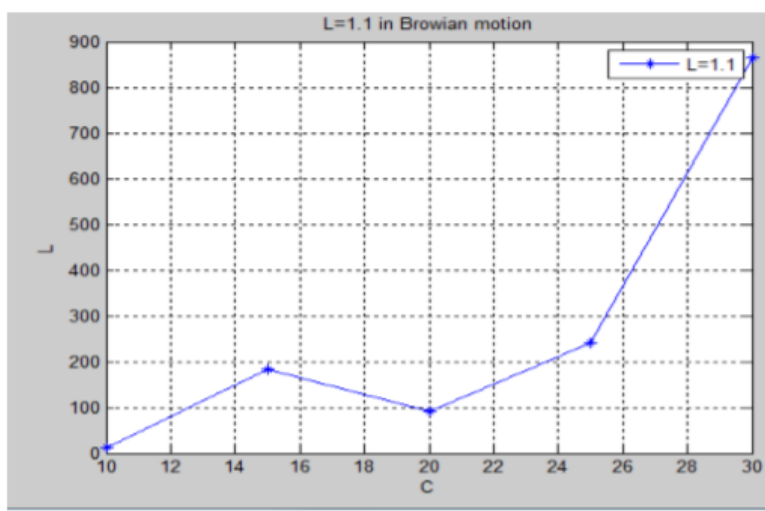

Figure 1L=1.1 in Brownian motion

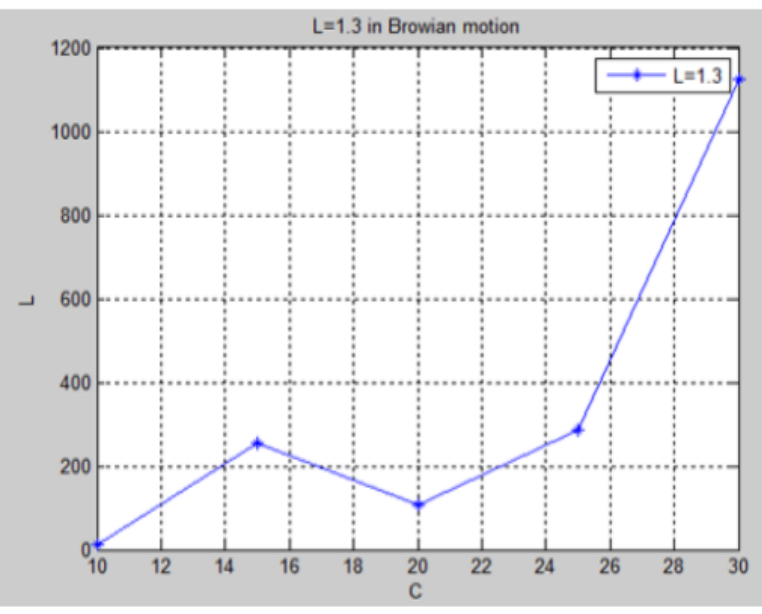

Figure $3 \mathrm{~L}=1.3$ in Brownian motion

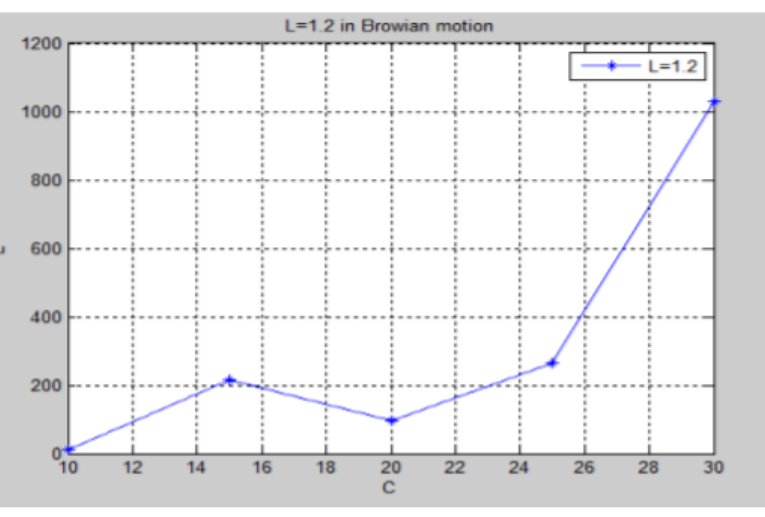

Figure2L=1.2 in Brownian motion

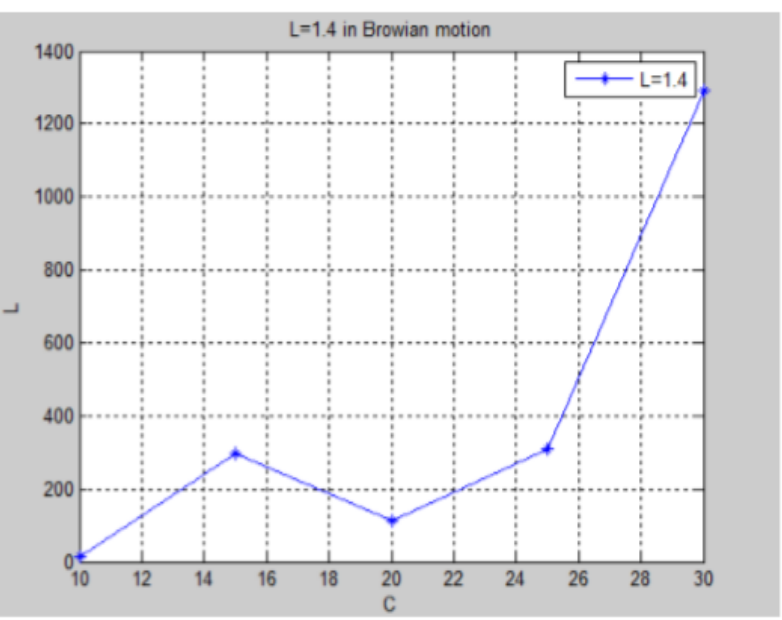

Figure4L=1.4 in Brownian motion

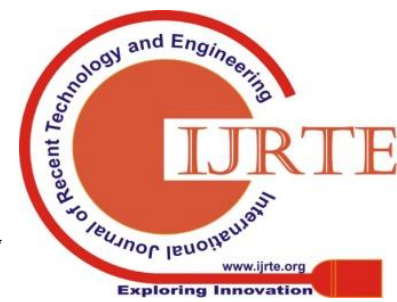




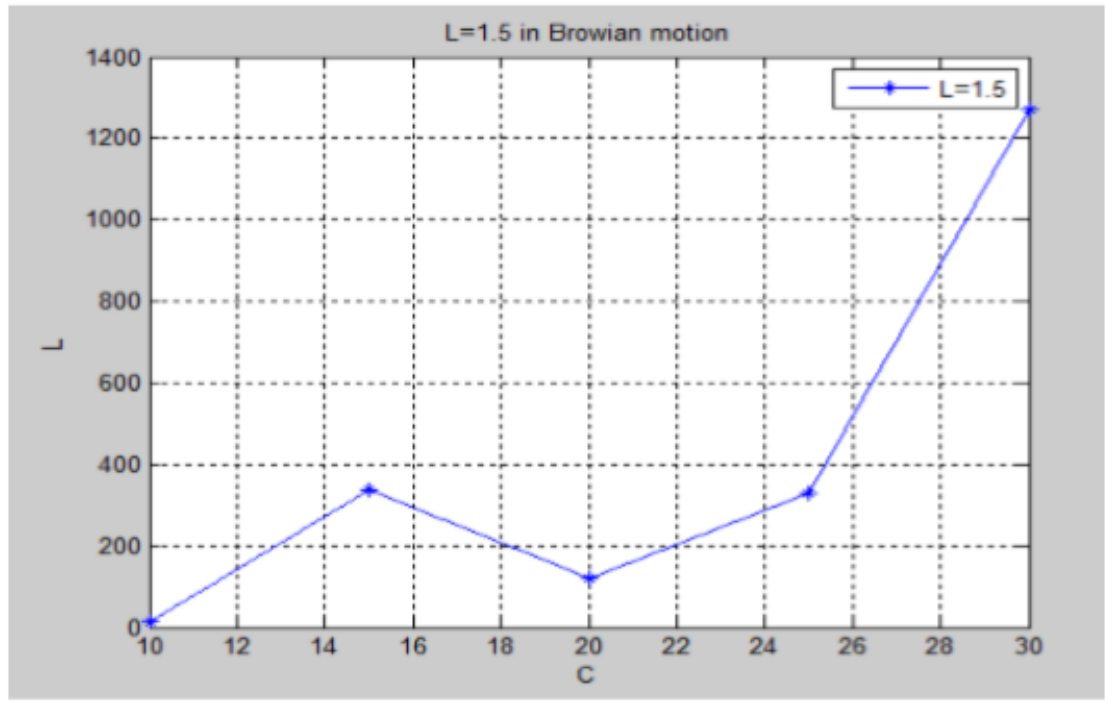

Figure $5 \mathrm{~L}=1.5$ in Brownian motion 